\title{
Author Correction: Subpixel three-dimensional laser imaging with a downscaled avalanche photodiode array using code division multiple access
}

Fan Xu, Yuan-Qing Wang, Xiao-Fei Zhang \& Cai-Yun Wang

Correction to: Communications Physics https://doi.org/10.1038/s42005-018-0096-2, published online 7 January 2019.

The second author of this manuscript has been designated as the corresponding author, and their contact details have been added to both the PDF and HTML versions of the Article.

The section "Corresponding author" has been changed to: Correspondence to Fan Xu or Yuan-Qing Wang in the HTML version of the article.

The correspondence footnote at the bottom of page 1 in the PDF version of the manuscript has been changed to Correspondence and requests for materials should be addressed to F.X. (email: xufan@nuaa.edu.cn) or to Y.-Q.W. (email: yqwang@nju.edu.cn).

Published online: 28 January 2021

\footnotetext{
(c) Open Access This article is licensed under a Creative Commons Attribution 4.0 International License, which permits use, sharing, adaptation, distribution and reproduction in any medium or format, as long as you give appropriate credit to the original author(s) and the source, provide a link to the Creative Commons license, and indicate if changes were made. The images or other third party material in this article are included in the article's Creative Commons license, unless indicated otherwise in a credit line to the material. If material is not included in the article's Creative Commons license and your intended use is not permitted by statutory regulation or exceeds the permitted use, you will need to obtain permission directly from the copyright holder. To view a copy of this license, visit http://creativecommons.org/licenses/by/4.0/.
}

(C) The Author(s) 2021 